\title{
Role of Dietary Protein and Muscular Fitness on Longevity and Aging
}

\author{
Barbara Strasser ${ }^{1}$, Konstantinos Volaklis ${ }^{2}$, Dietmar Fuchs ${ }^{3}$, Martin Burtscher ${ }^{4}$ \\ ${ }^{1}$ Division of Medical Biochemistry, Biocenter, Medical University Innsbruck, Austria \\ ${ }^{2}$ Department of Prevention and Sports Medicine, TUM, Munich, Germany \\ ${ }^{3}$ Division of Biological Chemistry, Biocenter, Medical University Innsbruck, Austria \\ ${ }^{4}$ Department of Sport Science, Medical Section, University Innsbruck, Austria
}

[Received January 14, 2017; Revised January 28, 2017; Accepted February 2, 2017]

\begin{abstract}
Muscle atrophy is an unfortunate effect of aging and many diseases and can compromise physical function and impair vital metabolic processes. Low levels of muscular fitness together with insufficient dietary intake are major risk factors for illness and mortality from all causes. Ultimately, muscle wasting contributes significantly to weakness, disability, increased hospitalization, immobility, and loss of independence. However, the extent of muscle wasting differs greatly between individuals due to differences in the aging process per se as well as physical activity levels. Interventions for sarcopenia include exercise and nutrition because both have a positive impact on protein anabolism but also enhance other aspects that contribute to well-being in sarcopenic older adults, such as physical function, quality of life, and anti-inflammatory state. The process of aging is accompanied by chronic immune activation, and sarcopenia may represent a consequence of a counterregulatory strategy of the immune system. Thereby, the kynurenine pathway is induced, and elevation in the ratio of kynurenine to tryptophan concentrations, which estimates the tryptophan breakdown rate, is often linked with inflammatory conditions and neuropsychiatric symptoms. A combined exercise program consisting of both resistance-type and endurance-type exercise may best help to ameliorate the loss of skeletal muscle mass and function, to prevent muscle aging comorbidities, and to improve physical performance and quality of life. In addition, the use of dietary protein supplementation can further augment protein anabolism but can also contribute to a more active lifestyle, thereby supporting well-being and active aging in the older population.
\end{abstract}

Key words: Aging, muscle, physical fitness, protein, kynurenine pathway, longevity

It is well known that people of all ages benefit from regular physical activity, which reduces the risk of coronary heart disease, hypertension, certain kinds of cancer, type 2 diabetes, and many other chronic diseases. Indeed, a low level of cardiorespiratory fitness is accepted nowadays as a powerful predictor of mortality in healthy as well as diseased individuals [1-3]. Muscular strength is an important component of physical fitness with an independent role in the prevention of many chronic diseases. Several epidemiological studies have shown that muscular weakness in middle-aged and older individuals is strongly related to functional limitations and physical disability [4-6]. Furthermore, epidemiological or shortterm studies indicate a potential beneficial effect of

*Correspondence should be addressed to: Barbara Strasser, ScDD, MPH, Division of Medical Biochemistry, Biocenter, Medical University Innsbruck, Innrain 80, A-6020 Innsbruck, AUSTRIA. Email direct: Barbara.Strasser@ i-med.ac.at

Copyright: () 2017 Strasser B et al. This is an open-access article distributed under the terms of the Creative Commons Attribution License, which permits unrestricted use, distribution, and reproduction in any medium, provided the original author and source are credited. 
increasing protein intake in older adults. Thus, the main goal of the present paper is to provide an overview on the role of physical exercise in muscle health in old age and to outline the clinical evidence of dietary protein intake to support healthy aging.

\section{Muscular strength and longevity}

A growing body of evidence suggests that muscular strength is inversely and independently associated with all-cause and cardiovascular mortality even after adjusting for cardiorespiratory fitness and other cofactors such as age, body fat, and smoking [7-12]. Several studies have shown that muscular strength is inversely associated with the incidence of many chronic diseases such as cardiovascular disease and stroke [13-17], hypertension [18], metabolic syndrome or hyperinsulinemia [19, 20], and type 2 diabetes [21]. In a large cohort study of one million Swedish men, muscle strength in young adulthood was an important predictor of coronary heart disease and stroke risk in later life, and this association persisted for both normal weight and obese individuals [14]. Recently, some researchers have also tried to relate muscular strength to the risk of suffering from multiple chronic diseases. In a cross-sectional study, including 1,145 subjects aged 50 years and older, Cheung et al. [22] found that handgrip strength in men was a more useful marker of multimorbidity than chronological age. Results from the KORA-Age study, a population-based study of 1,079 older people, demonstrated that low grip strength is inversely and independently associated with multimorbidity among older women after controlling for traditional confounders, as well as for inflammatory markers, telomere length, and levels of physical activity [23]. In addition, studies among older people have further suggested that there is a strong association between low muscle strength and both cognitive impairments and the risk of neurodegenerative diseases, such as dementia, Alzheimer's disease, and Parkinson disease [24-28]. All the above facts are of great interest from a public health perspective as muscular strength is a modifiable risk factor that can substantially influence chronic disease risk and premature mortality.

Multiple studies have examined the association between muscular strength and all-cause mortality, and all reported significant mortality reductions with increased levels of muscular strength [29-35]. This strong association persisted after adjusting for several cofactors and comorbidities and even after controlling for cardiorespiratory fitness. Especially in the oldest old population, poor handgrip strength has been linked with premature mortality, and this association tended to be stronger in women [36]. According to the findings of the Leiden 85-plus study [37], a population-based study that involved all $(\mathrm{n}=555)$ 85-year-old inhabitants of Leiden (The Netherlands), the risk of all-cause mortality was elevated by $35 \%$ and $104 \%$ in the lowest tertiles of handgrip strength among participants at age 85 and 89 years respectively. Interestingly, in this study, it was also shown that handgrip strength had a greater impact on mortality than the age of the participants. Two other studies clearly confirmed the strong association between muscular strength and mortality in older as well as in younger populations. A meta-analysis of 53,476 older individuals found that the hazard ratio for all-cause mortality comparing the weakest with the strongest quintile of grip strength was 1.67 after adjustment for age, gender, and body size [38]. In the Prospective UrbanRural Epidemiology (PURE) study, Leong et al. [11] followed 139,691 adults aged between 35 and 70 years living in 17 countries for a median time of 4 years in order to assess the prognostic value of grip strength on mortality. They demonstrated that grip strength was inversely associated with all-cause mortality, cardiovascular mortality, non-cardiovascular mortality, myocardial infarction, and stroke.

\section{Biology of muscle aging}

Human skeletal muscle inevitably undergoes remarkable changes with aging, characterized by a decline in muscle mass and strength of about $1 \%$ per year from the age of around 40 years [39]. Ultimately, muscle wasting will contribute significantly to frailty, immobility, and loss of independence. However, the extent of muscle wasting differs greatly between individuals due to differences in the aging process per se as well as in physical activity levels. Alterations in muscle architecture and fiber type composition, in tendon mechanical properties and vascular control of the contracting muscle are the most prominent characteristics associated with the decline in mass and functioning of aging skeletal muscle [40-42].

\section{Age-related changes in muscle architecture}

Distinct alterations in muscle architecture occur during aging resulting from inactivity (disuse atrophy) and originating from the aging process (senile sarcopenia) [42]. Whereas disuse atrophy is characterized only by a reduction in fiber size, sarcopenia exhibits both reduced fiber size and reduced fiber number. In addition, fascicle length and pennation angle decrease with aging [43]. The observation that the physiological cross-sectional area (muscle volume divided by fascicle length) declines with disuse and aging as well indicates a more pronounced loss of sarcomeres in parallel than sarcomeres in series (fascicle length) [42]. 


\section{Age-related changes in fiber type composition}

Reduced muscle volume in the elderly results from reductions in motor units and muscle fibers. Whereas the size of type 1 muscle fibers is nearly maintained, type 2 fiber size diminishes [44]. Nevertheless, the loss of fibers remains the main reason for the reduced muscle mass and strength with aging. Type 2 fibers seem to be particularly prone to increasing denervation with increasing age [45]. Fiber loss, however, is at least partly prevented because type 1 motor neurons form connections to denervated type 2 fibers. As a consequence, type 1 motor neurons become enlarged at the expense of type 2 fibers [45]. Muscle unloading (disuse) provokes a slow-to-fast transition, indicated by the elevation of fast myosin heavy chain (MHC) isoforms as well as fast myosin light chain (MLC) isoforms [46]. In contrast to disuse, aging per se results in a fast-to-slow transition, partly explained by the denervation of type 2 fibers and the glycation of the MHC [47].

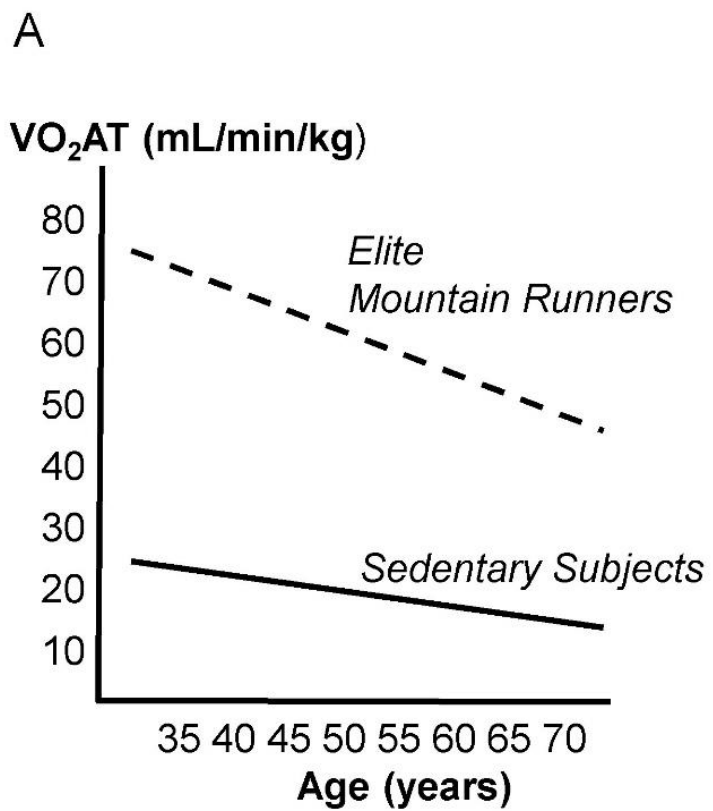

B

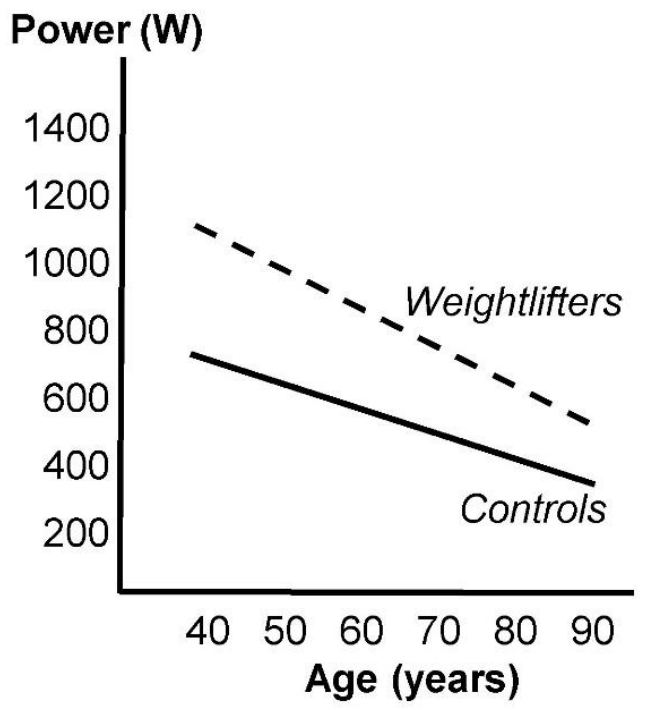

Figure 1. Age-related decline of endurance and strength performance in trained versus untrained subjects. Age-related decline in the anaerobic threshold $\left(\mathrm{VO}_{2} \mathrm{AT}\right)$ in Master's mountain runners and sedentary subjects (A) and peak power in Master's weight lifters and sedentary control subjects (B); (modified from ref. 58, 59).

\section{Mechanisms proposed}

Several mechanisms besides physical inactivity may explain aging-related muscle wasting. Age-related changes in the cerebral cortex have been proposed as a potential contributing factor, although no significant loss of motor cortical neurons seems to occur there [48]. However, there is a progressive loss of motor units (MUs) during the first five or six decades of life, which accelerates thereafter [49]. Axonal atrophy with aging may result from reduced axonal transport, degeneration of mitochondria, and accumulations of filaments also seen in neurodegenerative diseases [50]. Consequently, a denervation of type 2 fibers and their reinnervation by type 1 MUs probably develops in relation to the alterations in testosterone and estrogen (explaining sex differences), thyroid hormone levels, mitochondrial dysfunction, oxidative stress, low-grade inflammation, and insulin resistance [51]. In particular, the functional deterioration of mitochondria with aging and the related increase in oxidative stress may represent an important pathophysiological process of aging [52]. In addition, vasodilation and vascular control seem to be compromised in the aging skeletal muscle contributing to 
the decline in exercise performance. Responsible mechanisms may include smaller and stiffer vessels, impaired endothelium-dependent vasodilation, increased sympathetic vasoconstriction, alterations in metabolic or myogenic control, and diminished effectiveness of the skeletal muscle pump [42]. Most importantly, lifestyle characteristics such as physical activity and dietary habits have the potential to modify the aging process significantly.

\section{Physiological response to exercise training}

The rapid and pronounced effects of resistance training (concentric and/or eccentric) on strength and muscle mass in healthy adults are as well established as the beneficial implications of endurance exercise on the cardiovascular and skeletal muscle systems. Mitochondrial biogenesis promoted by exercise (endurance and/or strength) contributes significantly to the beneficial outcomes of exercise training [53]. There is also convincing evidence that resistance training of sufficient intensity is an effective measure for counteracting muscle wasting and frailty in very old people [54]. Apart from the aging process per se, disuse often contributes importantly to muscle wasting and decline in cardiovascular fitness. Examples of dramatic disuse-related reductions in strength and muscle mass are bed rest and weightlessness [55]. In contrast, acute resistance exercise enhances myofibrillar muscle protein synthesis in young as well as in older individuals of both sexes [56]. Thus, physical inactivity promotes a circulus vitiosus in aging individuals, leading to coordinated deadaptation of the cardiovascular and skeletal muscle systems, which are in charge of oxygen delivery to and oxygen utilization in working muscles [57]. In contrast, exercise training counteracts this circulus vitiosus, resulting in coordinated beneficial adaptations of these systems [57]. The much higher physical fitness (strength and endurance) levels of aging athletes compared with their sedentary peers are largely explained by their regular high-intensity physical activity throughout the life span [58, 59] (Fig. 1).

\section{Resistance type of exercise}

A single bout of resistance training is associated with a two- to threefold increase in muscle protein synthesis, which may be additionally enhanced by the intake of a protein-rich diet $[60,61]$. Elderly sedentary subjects can achieve up to more than 50\% strength gain even after 6 weeks of resistance training when performing two or three sessions per week applying a sufficiently high intensity (about $70-80 \%$ of maximal strength) [62]. To cause essential hypertrophy of muscle fibers, additional new myonuclei are necessary [63]. Skeletal muscle fibers are multinucleated, and these myonuclei are post-mitotic and cannot proliferate. Thus, for repair and renewal of myofibers, myogenic progenitor cells, termed satellite cells, are competent [64]. These satellite cells are in a quiescent state and only become activated when exposed to stress such as weight bearing or trauma resulting in proliferation and differentiation into new myonuclei, which fuse with existing muscle fibers [64]. It is believed that the increase in the number of satellite cells in response to various types of resistance training is different between young and older individuals, likely representing a limiting factor for muscle fiber hypertrophy in the elderly [63]. With regard to gender, resistance training has been shown to increase the myonuclear and satellite cell contents of type II muscle fibers and related muscle mass with no differences between older men and women [65]. Finally, resistance training also has the potential to increase respiratory capacity and the intrinsic function of mitochondria of skeletal muscles [66].

\section{Endurance type of exercise}

Endurance exercise training is the method of choice to maintain or improve cardiovascular fitness. Aerobic capacity $\left(\mathrm{VO}_{2} \mathrm{max}\right)$ has been shown to improve greatly in young as well as older (about 70 years) subjects in response to 12 weeks of endurance training [67]. There was a linear increase in $\mathrm{VO}_{2} \max$ during the 12-week training period, finally amounting to $30 \%$ improvement in the older group. Although this $\mathrm{VO}_{2}$ max increase was mainly achieved (about 70\%) by an increase in maximal cardiac output, oxygen extraction in working muscles significantly contributed to the improvement in aerobic capacity [67]. These training adaptations occurring in skeletal muscle contribute importantly to the ability to perform sustained exercise [57]. Muscle adaptations to repeated bouts of endurance exercise include increased capillary supply, elevations in key enzyme activities of the mitochondrial electron transport chain, and related enhancement in mitochondrial protein accumulation [57]. As a consequence, trained muscles at the same exercise intensity show a higher rate of fat oxidation, less use of muscle glycogen, and less lactate production, all contributing to improved exercise tolerance. Endurance exercise interventions have been reported to increase mitochondrial content on account of upregulation of transcriptional regulators of mitochondrial biogenesis [68]. The authors observed marked increases in the gene expression of peroxisome proliferator-activated receptor$\gamma$ coactivator-1 (PGC-1 $\alpha$ ) by $50 \%$ and of mitochondrial transcription factor A (TFAM) comparable to that found in older subjects after a similar exercise intervention [69]. Taken together, a combined exercise program consisting of both resistance-type and endurance-type exercise may 
best help to ameliorate the loss in skeletal muscle mass and function, prevent muscle aging comorbidities, and improve physical performance and quality of life.

\section{Dietary protein, muscle, and healthy aging}

Protein nutrition is an important component of the diet of older individuals. Protein is an essential nutrient; thus, at least a minimal amount of protein intake is necessary to support healthy living. However, older individuals are at high risk of insufficient protein intake, most probably as a consequence of aging malnutrition and anabolic resistance in aged muscle [70]. Furthermore, concomitant inflammation observed in chronic diseases leads to protein degradation and reduced skeletal muscle protein synthesis (MPS) and, consequently, to higher protein requirements [71]. Therefore, the current recommended dietary allowance (RDA) for protein of 0.8 grams of protein per kilogram of body mass per day might not be adequate for maintaining muscle and bone health in old age [72]. Recent research has provided evidence of the additional benefits of a greater dietary protein intake (i.e., $1.5 \mathrm{~g} / \mathrm{kg}$ body mass/day) beyond the prevention of sarcopenia [73], most relevant in both the genesis of and recovery from fractures $[74,75]$. Still, one of the major issues regarding protein intake is identifying how proteins derived from animal and plant sources differ in their capacity to enhance immunity in elderly people and how much protein is needed as the combination of exercise and protein ingestion has a positive, often synergistic effect on MPS [76-78].

\section{Anabolic resistance of MPS with aging - the importance of exercise}

With aging, a progressive loss of skeletal muscle mass (defined as sarcopenia) occurs at a rate of 3-8\% each decade after the age of 30 years [79], which has been attributed to impaired skeletal MPS, triggered by reduced amino acid delivery to aged skeletal muscle [80]. Older people appear to have a blunted muscle protein synthetic response to the two main anabolic stimuli, protein administration [81] or resistance exercise [82]. Several factors may influence the stimulation of MPS after a protein meal that may lead to anabolic resistance with aging. These include impairments in protein digestion and amino acid absorption [83], postprandial muscle tissue perfusion [84], muscle uptake of dietary amino acids [85], or a reduced amount or activation of anabolic signaling proteins [81, 86]. However, Burd and colleagues highlighted the hypothesis that physical inactivity is a key factor responsible for the proposed anabolic resistance of MPS with aging [87]. Indeed, several studies have shown that physical exercise performed before protein intake augments muscle protein synthetic response to protein ingestion and allows more of the ingested protein-derived amino acids to be used for de novo MPS in aging muscle $[78,88]$. A recent study found that older individuals who are perhaps unable to consume large amounts of protein can still benefit from ingesting smaller amounts of protein before sleep by performing exercise beforehand, thereby increasing the overnight muscle protein synthetic response [76]. This simple strategy may help to preserve muscle mass and strength in the older population and, as such, support healthy aging.

\section{Clinical benefits of protein supplementation}

Muscle atrophy is an unfortunate effect of aging and many diseases and can compromise physical function and impair vital metabolic processes [89]. Interventions for sarcopenia include exercise and nutrition [90, 91], because both have a positive impact on protein anabolism but also enhance other aspects that contribute to wellbeing in sarcopenic older adults, such as physical function, quality of life, and anti-inflammatory state [92]. Resistance training leads to a genuine increase in lean body mass and muscle strength in healthy older adults and is therefore considered to be the best exercise method for the treatment of sarcopenia [93]. Growing evidence supports increasing muscle protein uptake through nutrient interventions coupled with appropriate contractile manipulation [94]. Of importance for older adults, low load weight lifting effectively stimulates the rates of MPS to a level comparable with traditional high loads, besides other benefits such as improved aerobic capacity [95].

In many wasting diseases, muscle atrophy can be attributed to detrimental metabolic changes inducing catabolic crises. For example, rapid muscle wasting occurs early in critical illness, the extent of which determines recovery and survival $[96,97]$. Thus, early interventions to enhance anabolism are required. Functional electrical stimulation has become a clinically established method to prevent the loss of muscle mass for patients who are not able to perform active exercise [98]. This technique appears to be a useful adjunct to reverse muscle wasting in long-term intensive care unit patients by reducing protein degradation and inflammation in postoperative patients, which can positively affect the immune and inflammatory response seen in critical illness [99]. Furthermore, protein energy malnutrition is a condition that affects many hospital patients and consists of a variety of alterations including decreased intake of calories and/or protein and excess weight loss [100]. Insufficient dietary intake is not only related to the development of sarcopenia [101], but is also a major risk factor for illness and mortality in older hospitalized 
medical patients [102]. In malnourished older patients, short-term protein supplementation solely significantly increased both dietary intake and lean body mass [103]. Furthermore, immunonutrition has become a popular approach to augment the immune response of medically ill, immobilized patients. However, in critical medical care settings, nourishment alone has not improved clinical outcomes in numerous controlled trials [104, 105]. Indeed, the results of a recent systematic review of randomized clinical trials demonstrates that, although nutritional interventions increase daily caloric and protein intake as well as body weight, there is little effect of nutritional support on clinical outcomes in malnourished medical inpatients [106]. Perhaps that aggressive nutrition might not be sufficient unless you train these patients, because low skeletal muscle area may play a significant role. Muscularity represents a potential new marker for identifying mortality risk but, more importantly, permits the early identification of patients who may benefit from integrated immune-modulating nutrition. High-quality randomized clinical trials are needed to fill this gap.

The aging muscle is also a significant predictor of falls and fractures associated with a loss of independence in old age $[107,108]$. Thus, anabolic interventions against sarcopenia are particularly relevant in this cohort, as it is more prevalent in older hip fracture patients [109]. Although protein energy undernutrition predicts poor outcome in hip fracture patients, increased energy and protein intake have a favorable effect on the postoperative course in older individuals with hip fractures [110]. In summary, clinicians should not overlook the benefit of combined exercise and protein ingestion. Muscle stimulation is essential in order to prevent muscle wasting, maintain normal muscle function, and reduce inflammation in hospitalized patients; these are crucial ways to attenuate infection development and mortality. In addition, there is a clear need for dietary protein intake above the current RDA in older individuals, especially during periods when musculoskeletal mass is compromised, such as immobilization, with experts recommending between 1.2 and $2.0 \mathrm{~g} / \mathrm{kg}$ body mass per day [111].

\section{Protein quantity, quality, and timing of consumption}

Several factors related to protein nutrition, including the dose, source, and timing of ingested protein, as well as the co-ingestion of other macronutrients may influence the magnitude of the muscle protein response to exercise. It is clear that the essential amino acids are critical for optimal stimulation of MPS. It is generally accepted that the optimal amount of protein ingestion following exercise to stimulate maximal rates of MPS is $\approx 20-25 \mathrm{~g}$ [112]. However, recent data suggest that this amount may be insufficient in the elderly [113]. Stimulation of MPS in older adults increases, even up to $40 \mathrm{~g}$ of protein intake during recovery from resistance-type exercise. Yet, consuming large protein quantities in a single meal may be difficult for older people [114]. To solve this problem, experts recommend the ingestion of "suboptimal" doses of protein via supplementation with specific amino acids such as leucine [115-117]. Leucine is a powerful signal for stimulation of the mammalian target of the rapamycin complex-1 (mTORC1) pathway, which is responsible for the initiation of protein translation and is thus often used as a proxy measure for MPS [118]. Animal proteins have a higher proportion of the amino acid leucine. Whey protein is most effective in stimulating post-exercise MPS when compared with casein or soy protein [119]. The timing of protein ingestion represents another important factor for muscle protein anabolism. Although isolated proteins (e.g., whey, soy) should be consumed during or immediately after an exercise bout, the ingestion of protein-dense foods, such as dairy and meat, should be 90-120 minutes prior to exercise [91]. Most important for older adults, however, is to consume an adequate amount of high-quality protein at each meal, in combination with physical exercise.

\section{Tryptophan-kynurenine metabolism and immune activation in aging}

Immune activation in aging influences the metabolism of amino acids [120]. Although less than 1\% of dietary tryptophan is utilized for protein synthesis, tryptophan metabolism could be of special relevance in the elderly. Essential amino acid tryptophan is not only the sole precursor of serotonin and thus important for mood and cognition, but it is also linked to inflammation and immune activation via the so-called kynurenine pathway (KP), which is often systemically upregulated when the immune response is activated [121]. Th1-type cytokine interferon-gamma, among other biochemical pathways, induces tryptophan breakdown by the enzyme indoleamine 2,3-dioxygenase (IDO-1). As a result of the accelerated IDO-1 activity, levels of indoleamines tryptophan and serotonin become diminished, and this may increase the risk of, e.g., cognitive impairments. The activated immune system in older persons can be detected by increased kynurenine to tryptophan concentrations (Fig. 2).

Energy restriction clearly results in low plasma tryptophan and hence its availability, which can undermine serotonin metabolism, the KP, and subsequently the immune system [122]. Furthermore, the flux of tryptophan down the hepatic KP is enhanced by competing amino acids such as leucine [123]. Although a high-protein diet provides more tryptophan for the KP, 
tryptophan availability to the brain is paradoxically decreased as tryptophan competes with the other large neutral amino acids (LNAA) for transport across the blood-brain barrier [124]. For example, a breakfast rich in proteins induces a significant decrease in the plasma total tryptophan to LNAA ratio [125]. Although these changes apply to acute protein intake, a high-protein intake limits tryptophan availability for the cerebral KP, may further influence serotonin synthesis, and can disturb memory and cognition as well as sleep and mood, which eventually increases the risk of development of dementia and depression (Fig. 3).

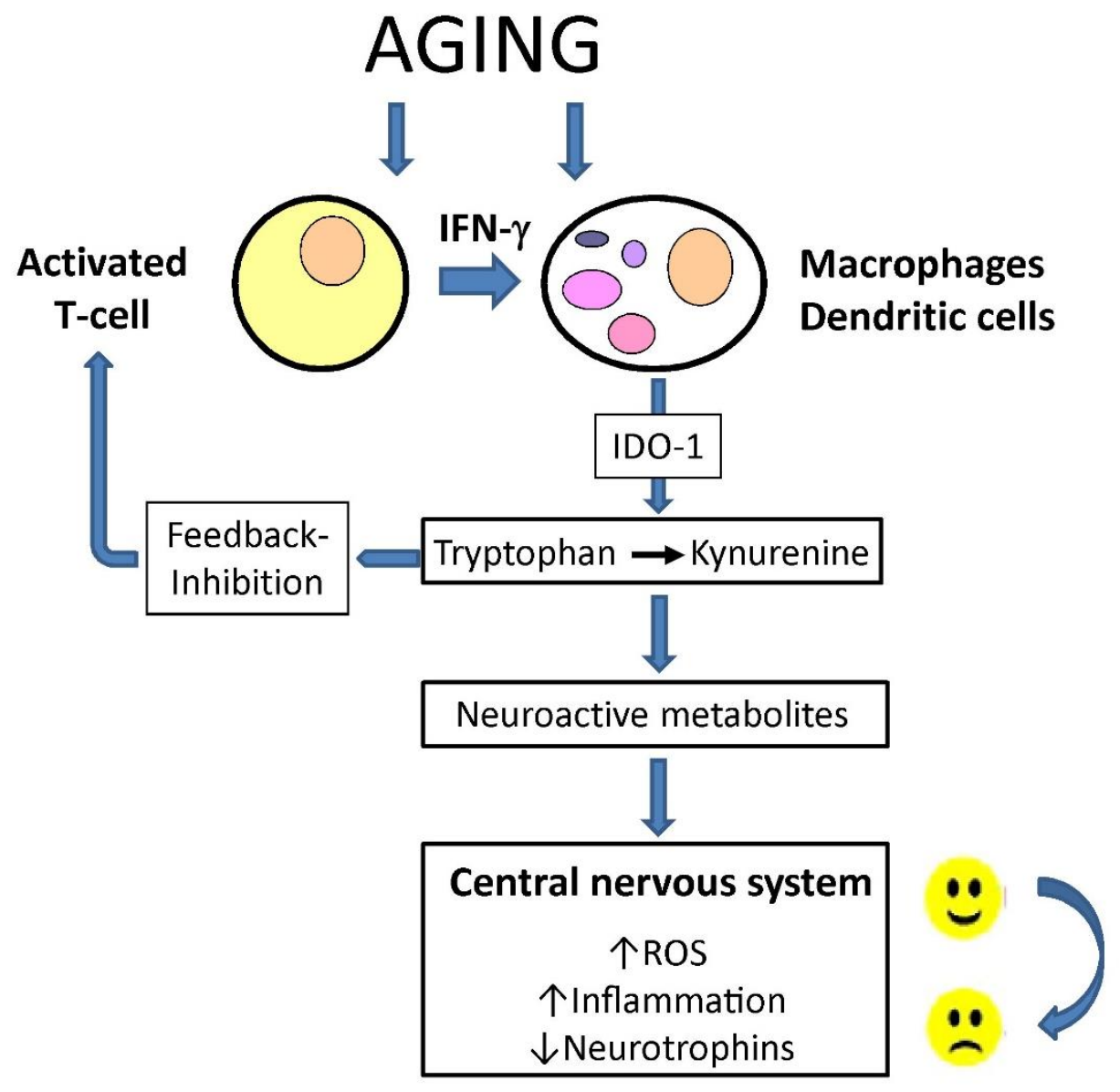

Figure 2. The induction of indoleamine 2,3-dioxygenase 1 (IDO1) by aging. The process of aging involves pro-inflammatory pathways which include activation of the T-cell-macrophage axis in the framework of the cell-mediated (Th1-type) immune response in which the formation of Th1-type cytokine interferon- $\gamma$ (IFN- $\gamma$ ) is of utmost relevance. IFN- $\gamma$ stimulates a broad spectrum of biochemical pathways that are directed to stop unwanted growth of pathogens or malignant cells. Among them, the conversion of essential amino acid tryptophan to kynurenine is a key element, which on the one hand is involved in a feedback inhibition of T-cell activation via regulatory T-cells and thus immunosuppressive. On the other hand, the catabolites generated by this strategy can impact on the central nervous system when neuroactive compounds accumulate and pro-inflammatory cascades including the formation of reactive oxygen species (ROS) interfere with neuroendocrine signaling, which controls mood and behavior. 


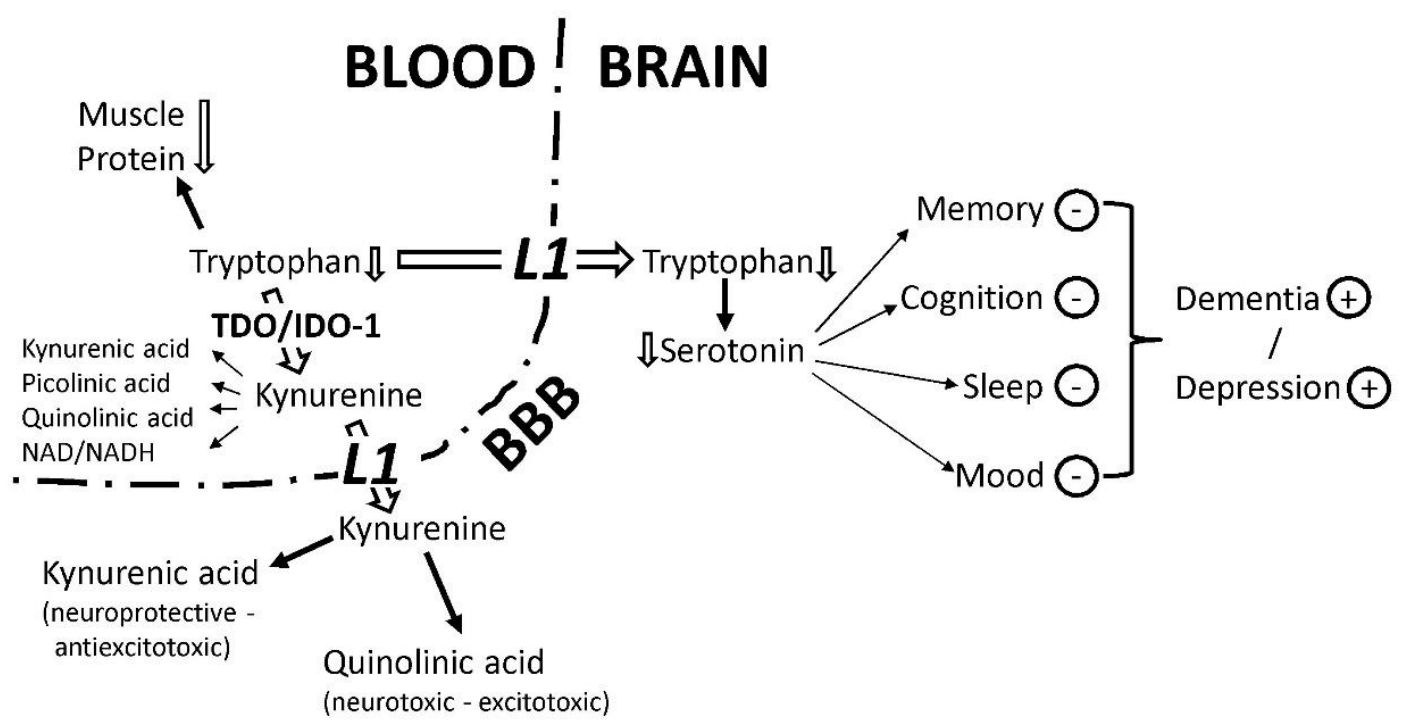

Figure 3. Tryptophan breakdown limits the availability of tryptophan for serotonin synthesis and increases the downstream production of neuroactive metabolites. Enhanced tryptophan breakdown by the enzymes tryptophan 2,3-dioxygenase (tryptophan pyrrolase, TDO) and/or indoleamine 2,3-dioxygenase-1 (IDO-1) can affect several body compartments including the brain. Thereby, various intermediate catabolites such as kynurenic acid, picolinic acid, and quinolinic acid are formed on the route to nicotinamide adenine dinucleotides. Tryptophan shortage during/after the pro-inflammatory response may reduce the availability of the essential amino acid for the biosynthesis of muscle proteins and can thus contribute to sarcopenia development with older age. For the transport of tryptophan and kynurenine into the brain to cross the blood-brain barrier (BBB), the leucine-preferring L1 system is utilized in competition with the so-called large neutral amino acids (LNAA). Once arrived in the brain, astrocytes are able to convert kynurenine to neuroprotective kynurenic acid, whereas glial cells primarily produce its neurotoxic counterpart quinolinic acid. Alternatively, tryptophan is converted by the tryptophan 5-monooxygenase to 5-hydroxytryptophan, which decarboxylates to the product serotonin (5-hydroxytryptamin), an important neurotransmitter and precursor of the sleep hormone melatonin. If brain tryptophan is low, serotonin also decreases and can disturb memory and cognition as well as sleep and mood, which finally increase the risk of development of dementia and depression.

On the other hand, moderate physical exercise, a potent stimulus to modulate tryptophan metabolism, could be helpful in improving mood status [126]. During exercise, the entry of tryptophan into the brain through the blood-brain barrier is favored by increased muscle use of branched-chain amino acids (BCAAs) and elevated plasma fatty acids. This elevates the ratio of unbound tryptophan to BCAA followed by a substantial increase in tryptophan availability to the brain, consequently leading to higher serotonin concentrations in some areas of the brain [127]. Recent results show that regular endurance exercise also causes adaptations in kynurenine metabolism by increased skeletal muscle kynurenine aminotransferase expression, which shifts kynurenine metabolism away from neurotoxic kynurenine metabolites like quinolinic acid to the production of kynurenic acid. By this method, crossing of kynurenine through the blood-brain barrier and the disruption of neural plasticity are prevented, which can have implications for exercise recommendations for patients with depressive disorders [128].

\section{Tryptophan-kynurenine, sarcopenia, and longevity}

The process of aging is accompanied by chronic immune activation and inflammation, and sarcopenia may represent a consequence of a counter-regulatory strategy of the immune system to dampen the process of immune activation. Thereby, tryptophan breakdown could 
represent an important checkpoint. Tryptophan deprivation can suppress immune activation processes via restriction of protein biosynthesis and the induction of regulatory T-cells by kynurenine metabolites [129, 130]. Accelerated tryptophan breakdown has been observed in healthy elderly individuals $[131,132]$. It may relate to specific clinical diagnoses that are common in old age such as cardiovascular diseases, chronic infections, or cancer. Likewise, not only loss of immunocompetence, but also decline in cognitive abilities and memory and higher risk of depressive mood may develop on the basis of tryptophan deficiency due to accelerated breakdown. Thus, these symptoms may represent side-effects of the immunobiochemical events that derive from chronic immune activation.

For a long time, immunosuppressive and/or antiinflammatory therapy has been discussed as a prophylactic and therapeutic approach to reduce ageassociated ailments and to increase life span [133, 134]. A higher rate of tryptophan breakdown and lower serum tryptophan levels have been described as being associated with a reduced residual life span in individuals with cardiovascular risk, and this was true not only for cardiovascular mortality but also for overall mortality $[135,136]$. Interestingly, the immunomodulatory properties of rapamycin and resveratrol are also responsible for their capacity to suppress tryptophan breakdown and IDO-1 activation, which were observed in human peripheral blood mononuclear cells in vitro [137, 138]. Whereas intense physical exercise may provoke chronic immune activation and may thus be involved in the development of impaired immune function [139], moderate physical activity and muscular training can be regarded as effective strategies against the overload with antioxidants, but to what extent they might be able to combat aging-associated alterations in tryptophan metabolism remains to be shown.

\section{Conclusion}

Muscular strength represents an independent role in the prevention of chronic diseases, whereas muscular weakness is strongly related to functional limitations and physical disability. Furthermore, low muscular strength has been recognized as an emerging risk factor for premature mortality beyond traditional risk factors such as hypercholesterolemia, obesity, hypertension, and smoking. For the above reasons and because muscle strength is known to decline with age, resistance-type and endurance-type exercise are currently prescribed by numerous health organizations in order to improve fitness and to counteract the adverse effects of aging on healthrelated parameters, including the risk of morbidity and mortality [140-142]. In addition, the use of dietary protein supplementation can further augment protein anabolism, but can also contribute to a more active lifestyle, thereby supporting well-being and active aging in the older population.

\section{References}

[1] Myers J, Prakash M, Froelicher V, Do D, Partington S, Atwood JE (2002). Exercise capacity and mortality among men referred for exercise testing. N Engl J Med, 346: 793-801.

[2] Sui X, LaMonte MJ, Blair SN (2007). Cardiorespiratory fitness and risk of nonfatal cardiovascular disease in women and men with hypertension. Am J Hypertens, 20: 608-15

[3] Kodama S, Saito K, Tanaka S, Maki M, Yachi Y, Asumi M, et al. (2009). Cardiorespiratory fitness as a quantitative predictor of all-cause mortality and cardiovascular events in healthy men and women: a meta-analysis. JAMA, 301: 2024-35.

[4] Hairi NN, Cumming RG, Naganathan V, Handelsman DJ, Le Couteur DG, Creasey H, et al. (2010). Loss of muscle strength, mass (sarcopenia), and quality (specific force) and its relationship with functional limitation and physical disability: the Concord Health and Ageing in Men Project. J Am Geriatr Soc, 58: 205562.

[5] Hirsch CH, Buzková P, Robbins JA, Patel KV, Newman AB (2012). Predicting late-life disability and death by the rate of decline in physical performance measures. Age Ageing, 41: 155-61.

[6] Rantanen T, Guralnik JM, Foley D, Masaki K, Leveille S, Curb JD, et al. (1999). Midlife hand grip strength as a predictor of old age disability. JAMA, 281: 558-60.

[7] Artero EG, Lee DC, Ruiz JR, Sui X, Ortega FB, Church TS, et al. (2011). A prospective study of muscular strength and all-cause mortality in men with hypertension. J Am Coll Cardiol, 57: 1831-37.

[8] Ruiz JR, Sui X, Lobelo F, Morrow JR, Jackson W, Sjoestroem M, et al. (2008). Association between muscular strength and mortality in men: prospective cohort study. BMJ, 337: a439.

[9] Ruiz JR, Sui X, Lobelo F, Lee DC, Morrow JR Jr, Jackson AW, et al. (2009). Muscular strength and adiposity as predictors of adulthood cancer mortality in men. Cancer Epidemiol Biomarkers Prev, 18: 1468-76.

[10] Ortega F, Silventoinen K, Tynelius P, Rasmussen F (2012). Muscular strength in male adolescents and premature death: cohort study of one million participants. BMJ, 345: e7279.

[11] Leong DP, Teo KK, Rangarajan S, Lopez-Jaramillo P, Avezum A Jr, Orlandini A, et al.; Prospective Urban Rural Epidemiology (PURE) Study investigators (2015). Prognostic value of grip strength: findings from the prospective urban rural epidemiology study. Lancet, 386: 266-73.

[12] Volaklis K, Halle M, Meisinger C (2015). Muscular strength as a strong predictor of mortality: a narrative review. Eur J Intern Med, 26: 303-10. 
[13] Tanasescu M, Leitzmann M, Rimm E, Willet W, Stampfer M, Hu F (2002). Exercise type and intensity in relation to coronary heart disease in men. JAMA, 288: 1994-2000.

[14] Silventoinen K, Magnusson PK, Tynelius P, Batty GD, Rasmussen F (2009). Association of body size and muscle strength with incidence of coronary heart disease and cerebrovascular diseases: a populationbased cohort study of one million Swedish men. Int $\mathbf{J}$ Epidemiol, 38: 110-18.

[15] Shrier I (2010). Muscle strength and body size and later cerebrovascular and coronary heart disease. Clin J Sports Med, 20: 131.

[16] Timpka S, Petersson I, Zhou C, Englund M (2014). Muscle strength in adolescent men and risk of cardiovascular disease events and mortality in middle age: a prospective cohort study. BMC Med, 12: 62.

[17] Åberg ND, Kuhn HG, Nyberg J, Waern M, Friberg P, Svensson J, et al. (2015). Influence of cardiovascular fitness and muscle strength in early adulthood on longterm risk of stroke in Swedish men. Stroke, 46: 176976.

[18] Maslow AL, Sui X, Colabianchi N, Hussey J, Blair SN (2010). Muscular strength and incident hypertension in normotensive and prehypertensive men. Med Sci Sports Exerc, 42: 288-95.

[19] Churilla JR, Magyari PM, Ford ES, Fitzhugh EC, Johnson TM (2012). Muscular strengthening activity patterns and metabolic health risk among US adults. $\mathrm{J}$ Diabetes, 4: 77-84.

[20] Jurca R, Lamonte MH, Barlow CE, Kampert JB, Church TS, Bair SN (2005). Association of muscular strength with incidence of metabolic syndrome in men. Med Sci Sports Exerc, 37: 1849-55.

[21] Grøntved A, Pan A, Mekary RA, Stampfer M, Willett WC, Manson JE, et al. (2014). Muscle-strengthening and conditioning activities and risk of type 2 diabetes: a prospective study in two cohorts of US Women. PLoS Med, 11: e1001587.

[22] Cheung CL, Nguyen US, Au E, Tan K, Kung A (2013). Association of handgrip strength with chronic diseases and multimorbidity: a cross-sectional study. Age, 35: 929-41.

[23] Volaklis KA, Halle M, Thorand B, Peters A, Ladwig $\mathrm{KH}$, Schulz H, et al. (2016). Handgrip strength is inversely and independently associated with multimorbidity among older women: Results from the KORA-Age study. Eur J Intern Med, 31:35-40.

[24] Boyle PA, Buchman AS, Wilson RS, Leurgans SE, Bennett DA (2009). Association of muscle strength with the risk of Alzheimer disease and the rate of cognitive decline in community-dwelling older persons. Arch Neurol, 66: 1339-44.

[25] Shin HY, Kim SW, Kim JM, Shin IS, Yoon JS (2012). Association of grip strength with dementia in a Korean older population. Int J Geriatr Psychiatry, 27: 500-5.

[26] Gustafsson H, Aasly J, Stråhle S, Nordström A, Nordström P (2015). Low muscle strength in late adolescence and Parkinson disease later in life. Neurology, 84: 1862-69.
[27] Buchman AS, Wilson RS, Boyle PA, Bienias JL, Bennett DA (2007). Grip strength and the risk of incident Alzheimer`s disease. Neuroepidemiology, 29: 66-73.

[28] Alfaro-Acha A, Al Snih S, Raji MA, Kuo YF, Markides KS, Ottenbacher KJ (2006). Handgrip strength and cognitive decline in older Mexican-Americans. J Gerontol A Biol Sci Med Sci, 61: 859-65.

[29] Fujita Y, Nakamura Y, Hiraoka J, Kobayashi K, Sakata K, Nagai M, et al. (1995). Physical-strength tests and mortality among visitors to health-promotion centers in Japan. J Clin Epidemiol, 48: 1349-59.

[30] Laukkanen P, Heikkinen E, Kauppinen M (1995). Muscle strength and mobility as predictors of survival in 74-84-year-old people. Age Aging, 24: 468-73.

[31] Rantanen T, Volpato S, Ferrucci L, Heikkinen E, Fried LP, Guralnik JM (2003). Handgrip strength and causespecific and total mortality in older disabled women: exploring the mechanism. J Am Geriatr Soc, 51: 63641.

[32] Rantanen T, Masaki K, He Q, Ross GW, Willcox BJ, White L (2012). Midlife muscle strength and human longevity up to age 100 years: a 44-year prospective study among a decedent cohort. Age, 34: 563-70.

[33] Gale RC, Martyn CN, Cooper C, Sayer AA (2007). Grip strength, body composition and mortality. Int $\mathbf{J}$ Epidemiol, 36: 228-35.

[34] Sasaki H, Kasagi F, Yamada M, Fujita S (2007). Grip strength predicts cause-specific mortality in middleaged and elderly persons. Am J Med, 120: 337-42.

[35] Katzmarzyk PT, Craig CL (2002). Musculoskeletal fitness and risk of mortality. Med Sci Sports Exerc, 34: 740-44.

[36] Arvandi M, Strasser B, Meisinger C, Volaklis K, Gothe RM, Siebert U, et al. (2016). Gender differences in the association between grip strength and mortality in older adults: results from the KORA-age study. BMC Geriatr, 16:201.

[37] Ling CH, Taekema D, de Craen AJ, Gussekloo J, Westendorp RG, Maier AB (2010). Handgrip strength and mortality in the oldest old population: the Leiden 85-plus study. Can Med Ass J, 182: 429-35.

[38] Cooper R, Kuh D, Hardy R; Mortality Review Group (2010). Objectively measured physical capability levels and mortality: systematic review and meta-analysis. BMJ, 341: c4467.

[39] Goodpaster BH, Park SW, Harris TB, Kritchevsky SB, Nevitt M, Schwartz AV, et al. (2006). The loss of skeletal muscle strength, mass, and quality in older adults: the Health, Aging and Body Composition Study. J Gerontol A Biol Sci Med Sci, 61: 1059-64.

[40] Lexell J (1995). Human aging, muscle mass, and fiber type composition. J Gerontol A Biol Sci Med Sci, 50: 11-6.

[41] Narici MV, Maganaris CN (2007). Plasticity of the muscle-tendon complex with disuse and aging. Exerc Sport Sci Rev, 35: 126-34.

[42] Proctor DN, Parker BA (2006). Vasodilation and vascular control in contracting muscle of the aging human. Microcirculation, 13: 315-27. 
[43] Narici MV, Maganaris CN, Reeves ND, Capodaglio P (2003). Effect of aging on human muscle architecture. J Appl Physiol (1985), 95: 2229-34.

[44] Porter MM, Vandervoort AA, Lexell J (1995). Aging of human muscle: structure, function and adaptability. Scand J Med Sci Sports, 5: 129-42.

[45] Vandervoort AA (2002). Aging of the human neuromuscular system. Muscle Nerve, 25: 17-25.

[46] Stevens L, Firinga C, Gohlsch B, Bastide B, Mounier Y, Pette D (2000). Effects of unweighting and clenbuterol on myosin light and heavy chains in fast and slow muscles of rat. Am J Physiol Cell Physiol, 279: C1558-63.

[47] Syrový I, Hodný Z (1992). Non-enzymatic glycosylation of myosin: effects of diabetes and ageing. Gen Physiol Biophys, 11: 301-7.

[48] Ward NS (2006). Compensatory mechanisms in the aging motor system. Ageing Res Rev, 5: 239-54.

[49] Gordon T, Hegedus J, Tam SL (2004). Adaptive and maladaptive motor axonal sprouting in aging and motoneuron disease. Neurol Res, 26: 174-85.

[50] Manini T, Hong SL, Clark BC (2013). Aging and muscle: a neuron's perspective. Curr Opin Clin Nutr Metab Care, 16: 21-6.

[51] Doria E, Buonocore D, Focarelli A, Marzatico F (2012). Relationship between human aging muscle and oxidative system pathway. Oxid Med Cell Longev, 2012: 830257.

[52] Gheller BJF, Riddle ES, Lem MR, Thalacker-Mercer AE (2016). Understanding age-related changes in skeletal muscle metabolism: differences between females and males. Ann Rev Nutr, 36: 129-56.

[53] Drake JC, Wilson RJ, Yan Z (2016). Molecular mechanisms for mitochondrial adaptation to exercise training in skeletal muscle. FASEB J, 30: 13-22.

[54] Fiatarone MA, O'Neill EF, Ryan ND, Clements KM, Solares GR, Nelson ME, et al. (1994). Exercise training and nutritional supplementation for physical frailty in very elderly people. N Engl J Med, 330: 1769-75.

[55] Ferrando AA, Lane HW, Stuart CA, Davis-Street J, Wolfe RR (1996). Prolonged bed rest decreases skeletal muscle and whole body protein synthesis. Am J Physiol Endocrinol Metab, 270: E627-33.

[56] Hasten DL, Pak-Loduca J, Obert KA, Yarasheski KE (2000). Resistance exercise acutely increases MHC and mixed muscle protein synthesis rates in 78-84 and 2332 yr olds. Am J Physiol Endocrinol Metab, 278: E62026.

[57] Burtscher M (2013). Exercise limitations by the oxygen delivery and utilization systems in aging and disease: coordinated adaptation and deadaptation of the lungheart muscle axis - a mini-review. Gerontology, 59: 289-96.

[58] Burtscher M, Förster H, Burtscher J (2008). Superior endurance performance in aging mountain runners. Gerontology, 54: 268-71.

[59] Faulkner JA, Davis CS, Mendias CL, Brooks SV (2008). The aging of elite male athletes: age-related changes in performance and skeletal muscle structure and function. Clin J Sport Med, 18: 501-7.
[60] Holm L, van Hall G, Rose A.J, Miller BF, Doessing S, Richter EA, et al. (2010). Contraction intensity and feeding affect collagen and myofibrillar protein synthesis rates differently in human skeletal muscle. Am J Physiol Endocrinol Metab, 298: E257-69.

[61] West DW, Burd NA, Coffey VG, Baker SK, Burke LM, Hawley JA, et al. (2011). Rapid aminoacidemia enhances myofibrillar protein synthesis and anabolic intramuscular signaling responses after resistance exercise. Am J Clin Nutr, 94: 795-803.

[62] Bautmans I, Van Puyvelde K, Mets T (2009). Sarcopenia and functional decline: pathophysiology, prevention and therapy. Acta Clin Belg, 64: 303-16.

[63] Snijders T, Verdijk LB, van Loon LJ (2009). The impact of sarcopenia and exercise training on skeletal muscle satellite cells. Ageing Res Rev, 8: 328-38.

[64] Hawke TJ, Garry DJ (2001). Myogenic satellite cells: physiology to molecular biology. J Appl Physiol, 91: 534-51.

[65] Leenders M, Verdijk LB, van der Hoeven L, van Kranenburg J, Nilwik R, van Loon LJ (2013). Elderly men and women benefit equally from prolonged resistance-type exercise training. J Gerontol A Biol Sci Med Sci, 68: 769-79.

[66] Porter C, Reidy PT, Bhattarai N, Sidossis LS, Rasmussen BB (2015). Resistance exercise training alters mitochondrial function in human skeletal muscle. Med Sci Sports Exerc, 47: 1922-31.

[67] Murias JM, Kowalchuk JM, Paterson DH (2010). Time course and mechanisms of adaptations in cardiorespiratory fitness with endurance training in older and young men. J Appl Physiol, 108: 621-27.

[68] Broskey NT, Greggio C, Boss A, Boutant M, Dwyer A, Schlueter L, et al. (2014). Skeletal muscle mitochondria in the elderly: effects of physical fitness and exercise training. J Clin Endocrinol Metab, 99: 1852-61.

[69] Short KR, Vittone JL, Bigelow ML, Proctor DN, Rizza RA, Coenen-Schimke JM, et al. (2003). Impact of aerobic exercise training on age-related changes in insulin sensitivity and muscle oxidative capacity. Diabetes, 52: 1888-96.

[70] Landi F, Calvani R, Tosato M, Martone AM, Ortolani E, Savera G, et al. (2016). Protein intake and muscle health in old age: From Biological Plausibility to Clinical Evidence. Nutrients, 8: pii: E295.

[71] Draganidis D, Karagounis LG, Athanailidis I, Chatzinikolaou A, Jamurtas AZ, Fatouros IG (2016). Inflammaging and Skeletal Muscle: Can protein intake make a difference? J Nutr, 146: 1940-52.

[72] Baum JI, Kim IY, Wolfe RR (2016). Protein consumption and the elderly: What is the optimal level of intake? Nutrients, 8: pii: E359.

[73] Houston DK, Nicklas BJ, Ding J, Harris TB, Tylavsky FA, Newman AB, et al.; Health ABC Study (2008). Dietary protein intake is associated with lean mass change in older, community-dwelling adults: the Health, Aging, and Body Composition (Health ABC) Study. Am J Clin Nutr, 87: 150-5.

[74] Bonjour JP (2011). Protein intake and bone health. Int J Vitam Nutr Res, 81: 134-42. 
[75] Calvani R, Martone AM, Marzetti E, Onder G, Savera G, Lorenzi M, et al. (2014). Pre-hospital dietary intake correlates with muscle mass at the time of fracture in older hip-fractured patients. Front Aging Neurosci, 6: 269.

[76] Holwerda AM, Kouw IW, Trommelen J, Halson SL, Wodzig WK, Verdijk LB, et al. (2016). Physical activity performed in the evening increases the overnight muscle protein synthetic response to presleep Protein Ingestion in Older Men. J Nutr, 146: 1307-14.

[77] Tieland M, Dirks ML, van der Zwaluw N, Verdijk LB, van de Rest O, de Groot LC, et al. (2012). Protein supplementation increases muscle mass gain during prolonged resistance-type exercise training in frail elderly people: a randomized, double-blind, placebocontrolled trial. J Am Med Dir Assoc, 13: 713-9.

[78] Yang Y, Breen L, Burd NA, Hector AJ, ChurchwardVenne TA, Josse AR, et al. (2012). Resistance exercise enhances myofibrillar protein synthesis with graded intakes of whey protein in older men. Br J Nutr, 108: 1780-8.

[79] Marcell TJ (2003). Sarcopenia: causes, consequences, and preventions. J Gerontol A Biol Sci Med Sci, 58: M911-6.

[80] Moro T, Ebert SM, Adams CM, Rasmussen BB (2016). Amino acid sensing in skeletal muscle. Trends Endocrinol Metab, 27: 796-806.

[81] Cuthbertson D, Smith K, Babraj J, Leese G, Waddell T, Atherton P, et al. (2005). Anabolic signaling deficits underlie amino acid resistance of wasting, aging muscle. FASEB J, 19: 422-4.

[82] Kumar V, Selby A, Rankin D, Patel R, Atherton P, Hildebrandt W, et al. (2009). Age-related differences in the dose-response relationship of muscle protein synthesis to resistance exercise in young and old men. $\mathbf{J}$ Physiol, 587: 211-7.

[83] Boirie Y, Gachon P, Beaufrère B (1997). Splanchnic and whole-body leucine kinetics in young and elderly men. Am J Clin Nutr, 65: 489-95.

[84] Rasmussen BB, Fujita S, Wolfe RR, Mittendorfer B, Roy M, Rowe VL, et al. (2006). Insulin resistance of muscle protein metabolism in aging. FASEB J, 20: 7689.

[85] Dickinson JM, Drummond MJ, Coben JR, Volpi E, Rasmussen BB (2013). Aging differentially affects human skeletal muscle amino acid transporter expression when essential amino acids are ingested after exercise. Clin Nutr, 32: 273-80.

[86] Guillet C, Prod'homme M, Balage M, Gachon P, Giraudet C, Morin L, et al. (2004). Impaired anabolic response of muscle protein synthesis is associated with S6K1 dysregulation in elderly humans. FASEB J, 18: 1586-7.

[87] Burd NA, Gorissen SH, van Loon LJ (2003). Anabolic resistance of muscle protein synthesis with aging. Exerc Sport Sci Rev, 41: 169-73.

[88] Pennings B, Koopman R, Beelen M, Senden JM, Saris WH, van Loon LJ (2011). Exercising before protein intake allows for greater use of dietary protein-derived amino acids for de novo muscle protein synthesis in both young and elderly men. Am J Clin Nutr, 93: 32231 .

[89] Anker SD, Coats AJ, Morley JE, Rosano G, Bernabei R, von Haehling S, et al. (2014). Muscle wasting disease: a proposal for a new disease classification. $\mathbf{J}$ Cachexia Sarcopenia Muscle, 5: 1-3.

[90] Deutz NE, Bauer JM, Barazzoni R, Biolo G, Boirie Y, Bosy-Westphal A, et al. (2014). Protein intake and exercise for optimal muscle function with aging: recommendations from the ESPEN Expert Group. Clin Nutr, 33: 929-36.

[91] Paddon-Jones D, Campbell WW, Jacques PF, Kritchevsky SB, Moore LL, Rodriguez NR, et al. (2015). Protein and healthy aging. Am J Clin Nutr, pii: ajcn084061. [Epub ahead of print].

[92] Rondanelli M, Klersy C, Terracol G, Talluri J, Maugeri R, Guido D, et al. (2016). Whey protein, amino acids, and vitamin D supplementation with physical activity increases fat-free mass and strength, functionality, and quality of life and decreases inflammation in sarcopenic elderly. Am J Clin Nutr, 103: 830-40.

[93] Strasser B, Keinrad M, Haber P, Schobersberger W (2009). Efficacy of systematic endurance and resistance training on muscle strength and endurance performance in elderly adults--a randomized controlled trial. Wien Klin Wochenschr, 121: 757-64.

[94] Breen L, Phillips SM (2013). Interactions between exercise and nutrition to prevent muscle waste during ageing. Br J Clin Pharmacol, 75: 708-15.

[95] Burd NA, Andrews RJ, West DW, Little JP, Cochran AJ, Hector AJ, et al. (2012). Muscle time under tension during resistance exercise stimulates differential muscle protein sub-fractional synthetic responses in men. J Physiol, 590: 351-62.

[96] Puthucheary ZA, Rawal J, McPhail M, Connolly B, Ratnayake G, Chan P, et al. (2013). Acute skeletal muscle wasting in critical illness. JAMA, 310: 1591600.

[97] Moisey LL, Mourtzakis M, Cotton BA, Premji T, Heyland DK, Wade CE, et al.; Nutrition and Rehabilitation Investigators Consortium (NUTRIC) (2013). Skeletal muscle predicts ventilator-free days, ICU-free days, and mortality in elderly ICU patients. Crit Care 2013, 17: R206.

[98] Dirks ML, Wall BT, Snijders T, Ottenbros CL, Verdijk LB, van Loon LJ (2014). Neuromuscular electrical stimulation prevents muscle disuse atrophy during leg immobilization in humans. Acta Physiol, 210: 628-41.

[99] Strasser EM, Stättner S, Karner J, Klimpfinger M, Freynhofer M, Zaller V, et al. (2009). Neuromuscular electrical stimulation reduces skeletal muscle protein degradation and stimulates insulin-like growth factors in an age- and current-dependent manner: a randomized, controlled clinical trial in major abdominal surgical patients. Ann Surg, 249: 738-43.

[100] Thomas MN, Kufeldt J, Kisser U, Hornung HM, Hoffmann J, Andraschko M, et al. (2016). Effects of malnutrition on complication rates, length of hospital stay, and revenue in elective surgical patients in the GDRG-system. Nutrition, 32: 249-54. 
[101] Martone AM, Onder G, Vetrano DL, Ortolani E, Tosato M, Marzetti E, et al. (2013). Anorexia of aging: a modifiable risk factor for frailty. Nutrients, 5: 4126-33.

[102] Covinsky KE, Martin GE, Beyth RJ, Justice AC, Sehgal AR, Landefeld CS (1999). The relationship between clinical assessments of nutritional status and adverse outcomes in older hospitalized medical patients. J Am Geriatr Soc, 47: 532-8.

[103] Bos C, Benamouzig R, Bruhat A, Roux C, Valensi P, Ferrière F, et al. (2001). Nutritional status after shortterm dietary supplementation in hospitalized malnourished geriatric patients. Clin Nutr, 20: 225-33.

[104] Heyland D, Muscedere J, Wischmeyer PE, Cook D, Jones G, Albert M, et al.; Canadian Critical Care Trials Group (2013). A randomized trial of glutamine and antioxidants in critically ill patients. N Engl J Med, 368: 1489-97.

[105] van Zanten AR, Sztark F, Kaisers UX, Zielmann S, Felbinger TW, Sablotzki AR, et al. (2014). Highprotein enteral nutrition enriched with immunemodulating nutrients vs standard high-protein enteral nutrition and nosocomial infections in the ICU: a randomized clinical trial. JAMA, 312: 514-24.

[106] Bally MR, Blaser Yildirim PZ, Bounoure L, Gloy VL, Mueller B, Briel M, et al. (2016). Nutritional support and outcomes in malnourished medical inpatients: A systematic review and meta-analysis. JAMA Intern Med, 176: 43-53.

[107] Landi F, Liperoti R, Russo A, Giovannini S, Tosato M, Capoluongo E, et al. (2012). Sarcopenia as a risk factor for falls in elderly individuals: results from the ilSIRENTE study. Clin Nutr, 31: 652-8.

[108] Dyer SM, Crotty M, Fairhall N, Magaziner J, Beaupre LA, Cameron ID, et al.; Fragility Fracture Network (FFN) Rehabilitation Research Special Interest Group (2016). A critical review of the long-term disability outcomes following hip fracture. BMC Geriatr, 16: 158.

[109] Fiatarone Singh MA (2014). Exercise, nutrition and managing hip fracture in older persons. Curr Opin Clin Nutr Metab Care, 17: 12-24.

[110] Schürch MA, Rizzoli R, Slosman D, Vadas L, Vergnaud P, Bonjour JP (1998). Protein supplements increase serum insulin-like growth factor-I levels and attenuate proximal femur bone loss in patients with recent hip fracture. A randomized, double-blind, placebo-controlled trial. Ann Intern Med, 128: 801-9.

[111] Bauer J, Biolo G, Cederholm T, Cesari M, Cruz-Jentoft AJ, Morley JE, et al. (2013). Evidence-based recommendations for optimal dietary protein intake in older people: a position paper from the PROT-AGE Study Group. J Am Med Dir Assoc, 14: 542-59.

[112] Moore DR, Robinson MJ, Fry JL, Tang JE, Glover EI, Wilkinson SB, et al. (2009). Ingested protein dose response of muscle and albumin protein synthesis after resistance exercise in young men. Am J Clin Nutr, 89: 161-8.

[113] Churchward-Venne TA, Holwerda AM, Phillips SM, van Loon LJ (2016). What is the optimal amount of protein to support post-exercise skeletal muscle reconditioning in the older adult? Sports Med, 46: 1205-12.

[114] Drummond MJ (2015). A practical dietary strategy to maximize the anabolic response to protein in aging muscle. J Gerontol A Biol Sci Med Sci, 70: 55-6.

[115] Churchward-Venne TA, Breen L, Di Donato DM, Hector AJ, Mitchell CJ, Moore DR, Stellingwerff T, Breuille D, Offord EA, Baker SK, Phillips SM (2014). Leucine supplementation of a low-protein mixed macronutrient beverage enhances myofibrillar protein synthesis in young men: a double-blind, randomized trial. Am J Clin Nutr, 99: 276-86.

[116] Dickinson JM, Gundermann DM, Walker DK, Reidy PT, Borack MS, Drummond MJ, et al. (2014). Leucineenriched amino acid ingestion after resistance exercise prolongs myofibrillar protein synthesis and amino acid transporter expression in older men. J Nutr, 144: 1694702.

[117] Wall BT, Hamer HM, de Lange A, Kiskini A, Groen BB, Senden JM, et al. (2013). Leucine co-ingestion improves post-prandial muscle protein accretion in elderly men. Clin Nutr, 32: 412-9.

[118] Drummond MJ, Dreyer HC, Fry CS, Glynn EL, Rasmussen BB (2009). Nutritional and contractile regulation of human skeletal muscle protein synthesis and mTORC1 signaling. J Appl Physiol, 106: 1374-84.

[119] Tang JE, Moore DR, Kujbida GW, Tarnopolsky MA, Phillips SM (2009). Ingestion of whey hydrolysate, casein, or soy protein isolate: effects on mixed muscle protein synthesis at rest and following resistance exercise in young men. J Appl Physiol, 107: 987-92.

[120] Capuron L, Schroecksnadel S, Féart C, Aubert A, Higueret D, Barberger-Gateau P, et al. (2011). Chronic low-grade inflammation in elderly persons is associated with altered tryptophan and tyrosine metabolism: role in neuropsychiatric symptoms. Biol Psychiatry, 70: 175-82.

[121] Strasser B, Becker K, Fuchs D, Gostner JM (2017). Kynurenine pathway metabolism and immune activation: Peripheral measurements in psychiatric and co-morbid conditions. Neuropharmacology, 112(Pt B): 286-96.

[122] Strasser B, Berger K, Fuchs D (2014). Effects of a caloric restriction weight loss diet on tryptophan metabolism and inflammatory biomarkers in overweight adults. Eur J Nutr, 54: 101-7.

[123] Badawy AA (2017). Tryptophan availability for kynurenine pathway metabolism across the life span: Control mechanisms and focus on aging, exercise, diet and nutritional supplements. Neuropharmacology, 112(Pt B): 248-63.

[124] Strasser B, Fuchs D (2016). Diet versus exercise in weight loss and maintenance: Focus on tryptophan. Int J Tryptophan Res, 9: 9-16.

[125] Wurtman RJ, Wurtman JJ, Regan MM, McDermott JM, Tsay RH, Breu JJ (2003). Effects of normal meals rich in carbohydrates or proteins on plasma tryptophan and tyrosine ratios. Am J Clin Nutr, 77: 128-32. 
[126] Strasser B, Fuchs D (2015). Role of physical activity and diet on mood, behavior, and cognition. Neurol Psychiatry Brain Res, 21: 118-126.

[127] Meeusen R (2014). Exercise, nutrition and the brain. Sports Med, 44, Suppl 1: S47-56.

[128] Agudelo LZ, Femenía T, Orhan F, Porsmyr-Palmertz M, Goiny M, Martinez-Redondo V, et al. (2014). Skeletal muscle PGC- $1 \alpha 1$ modulates kynurenine metabolism and mediates resilience to stress-induced depression. Cell, 159: 33-45.

[129] Fallarino F, Grohmann U, Vacca C, Bianchi R, Orabona C, Spreca A, et al. (2002). T cell apoptosis by tryptophan catabolism. Cell Death Differ, 9: 1069-77.

[130] Munn DH, Sharma MD, Lee JR, Jhaver KG, Johnson TS, Keskin DB, et al. (2002). Potential regulatory function of human dendritic cells expressing indoleamine 2,3-dioxygenase. Science, 297: 1867-70.

[131] Frick B, Schroecksnadel K, Neurauter G, Leblhuber F, Fuchs D (2004). Increasing production of homocysteine and neopterin and degradation of tryptophan with older age. Clin Biochem, 37: 684-7.

[132] Pertovaara M, Raitala A, Lehtimäki T, Karhunen PJ, Oja SS, Jylhä M, et al. (2006). Indoleamine 2,3dioxygenase activity in nonagenarians is markedly increased and predicts mortality. Mech Ageing Dev, 127: 497-9.

[133] Harrison DE, Strong R, Sharp ZD, Nelson JF, Astle CM, Flurkey K, et al. (2009). Rapamycin fed late in life extends lifespan in genetically heterogeneous mice. Nature, 460: 392-5.

[134] Kaeberlein M (2010). Resveratrol and rapamycin: are they anti-aging drugs? Bioessays, 32: 96-9.

[135] Murr C, Grammer TB, Kleber ME, Meinitzer A, März W, Fuchs D (2015). Low serum tryptophan predicts higher mortality in cardiovascular disease. Eur J Clin Invest, 45: 247-54.

[136] Pedersen ER, Midttun $\varnothing$, Ueland PM, SchartumHansen H, Seifert R, Igland J, et al. (2011). Systemic markers of interferon- $\gamma$-mediated immune activation and long-term prognosis in patients with stable coronary artery disease. Arterioscler Thromb Vasc Biol, 31: 698-704.
[137] Schroecksnadel S, Sucher R, Kurz K, Fuchs D, Brandacher G (2011). Influence of immunosuppressive agents on tryptophan degradation and neopterin production in human peripheral blood mononuclear cells. Transpl Immunol, 25: 119-23.

[138] Wirleitner B, Schroecksnadel K, Winkler C, Schennach H, Fuchs D (2005). Resveratrol suppresses interferongamma-induced biochemical pathways in human peripheral blood mononuclear cells in vitro. Immunol Lett, 100: 159-63.

[139] Strasser B, Geiger D, Schauer M, Gatterer H, Burtscher M, Fuchs D (2016). Effects of exhaustive aerobic exercise on tryptophan-kynurenine metabolism in trained athletes. PLoS One, 11: e0153617.

[140] Williams MA, Haskell WL, Ades PA, Amsterdam EA, Bittner V, Franklin BA, et al.; American Heart Association Council on Clinical Cardiology; American Heart Association Council on Nutrition, Physical Activity, and Metabolism (2007). Resistance exercise in individuals with and without cardiovascular disease: 2007 update: a scientific statement from the American Heart Association Council on Clinical Cardiology and Council on Nutrition, Physical Activity, and Metabolism. Circulation, 116: 572-84.

[141] Nelson ME, Rejeski WJ, Blair SN, Duncan PW, Judge JO, King AC, et al.; American College of Sports Medicine; American Heart Association (2007). Physical activity and public health in older adults: recommendation from the American College of Sports Medicine and the American Heart Association. Circulation, 116: 1094-105.

[142] Garber CE, Blissmer B, Deschenes MR, Franklin BA, Lamonte MJ, Lee IM, et al.; American College of Sports Medicine (2011). American College of Sports Medicine position stand. Quantity and quality of exercise for developing and maintaining cardiorespiratory, musculoskeletal, and neuromotor fitness in apparently healthy adults: guidance for prescribing exercise. Med Sci Sports Exerc, 43: 133459. 